\title{
Dental Maturity in Saudi Children Using the Demirjian Method: A Comparative Study and New Prediction Models
}

\author{
Ziad D. Baghdadi \\ Department of Preventive Dentistry, Riyadh Colleges of Dentistry and Pharmacy, P.O. Box 67126, Riyadh 11596, Saudi Arabia \\ Correspondence should be addressed to Ziad D. Baghdadi; ziadbaghdadi@outlook.com
}

Received 27 December 2012; Accepted 18 January 2013

Academic Editors: M. Del Fabbro and J. H. Jeng

Copyright (C) 2013 Ziad D. Baghdadi. This is an open access article distributed under the Creative Commons Attribution License, which permits unrestricted use, distribution, and reproduction in any medium, provided the original work is properly cited.

\begin{abstract}
A sample of 422 dental panoramic radiographs from individuals of known age (from 4 to 14 yrs), sex (males: 217, females: 205), and ethnicity (Saudi) was collected. A dental maturation score for each individual was calculated using the Demirjian method. Age was then estimated using the original Demirjian curves and tables based on French-Canadian population and populationspecific curves and tables for Arab (Saudi and Kuwaiti) and European (Belgian) populations. The differences between dental age and chronological age were analyzed and compared using paired $t$-tests, one-way ANOVA test, and a post hoc Scheffé's test. The Demirjian method utilizing French-Canadian standards presented significant difference between dental age and chronological age for the total sample and in the vast majority of age groups in both sexes. The mean overestimation of age was about 10 months $(P<0.05)$. The tables designed specifically for Arab populations had a significantly lower error than the tables designed for FrenchCanadian and Belgian populations. The latter had the largest error in age predication. New age prediction models and maturation scores for Saudi population were developed based on the Demirjian method using multinomial functions.
\end{abstract}

\section{Introduction}

Several forms of biological age, such as skeletal, morphological, and dental, assess the physiological maturity of a child [1]. Dental age (DA) is an important factor to consider when treating malocclusion or inappropriate growth of the face [1-3]. DA as a means for determining chronological age is valuable in cases of adopted children, children who have committed legal offences, or in forensic cases. A scoring system, such as the Demirjian method, scores the different stages of tooth development resulting in a dental maturity score [4].

Systems based on the eruption of teeth are inaccurate methods of determining dental age because eruption is heavily influenced by environmental factors [3]. Tooth development is less affected by dental arch space, extraction of deciduous teeth, or tipping or impaction of teeth, which may influence the eruption process [3]. Reliable events in dental development, such as tooth calcification, allow for improved prediction of dental maturity [2]. The Demirjian method is highly accurate when evaluating young children $(<6.5)$, less so with older children [5].
In a study [6] that compared dental age to chronological age in Somali children to that of matched white Caucasian children in England, the mean difference found between dental age and chronological age was 1.01 years for Somali boys, 0.19 for Caucasian boys, 1.22 years for Somali girls, and 0.52 years for Caucasian girls. Somali children appear to be significantly more dentally mature than their Caucasian peers. Similarly, another study [7] tested the accuracy of the dental age estimation methods of Moorrees et al. and Demirjian on children of different ethnic groups in South Africa. Because the study found that the Moorrees et al. method consistently underestimated age and the Demirjian method overestimated age, dental age tables were developed specifically for these ethnic groups. When tested, these tables were found to be more accurate than either the Moorrees et al. or the Demirjian methods [8]. These findings suggest a need for population-specific dental development standards based on ethnicity to improve the accuracy of dental age assessment. The purpose of this cross-sectional study was to develop age prediction models for children, using the original Demirjian scores, by testing accuracy of the scores in Saudi Arabian children by comparing the dental age of different 


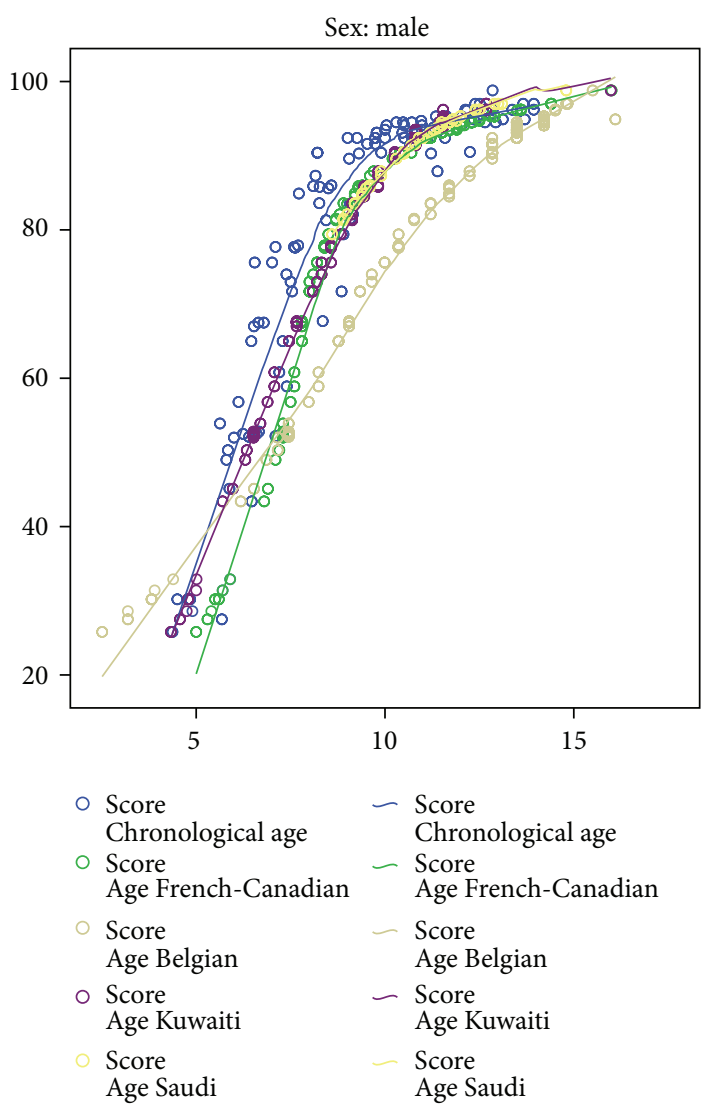

Figure 1: Comparison of the study population to the different existing curves-boys.

population-specific curves to the children' chronological ages.

\section{Methods}

The sample, 422 panoramic radiographs of 217 boys and 205 girls, was collected from university-based and private-based pediatric dental clinics. Children with systemic diseases that can affect development of teeth, mandibular hypodontia (except third molars), and low-quality radiographs were excluded. The children's ages ranged from 4 to 14 years.

The radiographs were divided into 10 groups by the child's chronological age, calculated by subtracting the date of the radiograph from the date of birth. Each group was comprised of radiographs from children of the same age (children were grouped by a span of 1 year starting from 4 years up to 14). Dental age assessment was performed according to the Demirjian method [1]. Briefly, the development of each left permanent mandibular tooth, except the third molar, was rated on an 8-stage scale from $\mathrm{A}$ to $\mathrm{H}$, and the criteria for the stages were given separately for each tooth. Each stage of the seven teeth was scored, and the sum of the scores resulted in an evaluation of the child's dental maturity, measured on a scale from 0 to 100 . The score of each child was then converted to dental age using standard tables for both boys and girls.

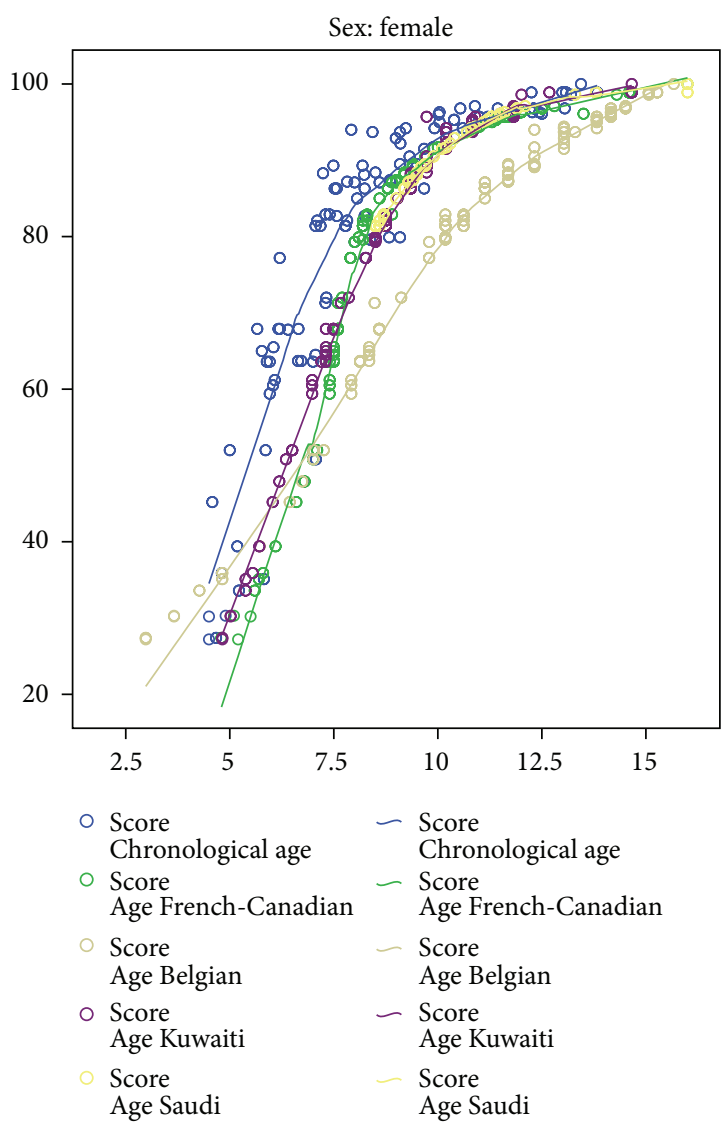

FIGURE 2: Comparison of the study population to the different existing curves-girls.

The data were stored and analyzed using statistical software SPSS ver. 19 (IBM Corp., Somers, NY, USA) and Minitab ver. 16 (Minitab Inc., State College, PA, USA). Paired $t$-tests were used to establish any differences between estimated ages obtained by the Demirjian scores and chronological ages for both sexes. The difference between dental age and chronological age using the different age groups for each gender was tabulated according to previously published tables calculated using a modified Demirjian method for European (Belgian) [9], other Arab (Kuwaiti) [10], and Saudi [11] children. Differences were compared using a one-way ANOVA and a post hoc Scheffe's test. Regression models explored calculations of age (taken as the dependent or response variable) and maturity score or dental age (taken as the independent or explanatory variables). Calculations were done separately for boys and girls. Level of significance was set at $P=0.05$.

Prior to collecting age assessment data, a reliability study assessed the magnitude of the intraobserver errors of interpretation and detection. Two calibrated examiners assessed the maturation stage of the seven left mandibular permanent teeth without the knowledge of chronological age or gender. To evaluate reproducibility, 25 radiographs (with 175 tooth-individual ratings) were randomly selected and assessed by both examiners. There were approximately four 
TABLE 1: Dental age (DA), chronological age (CA), and difference between dental age and chronological age.

\begin{tabular}{|c|c|c|c|c|c|c|}
\hline \multirow{2}{*}{ Age group } & \multirow{2}{*}{ Gender } & \multicolumn{3}{|c|}{ Mean (SD) } & \multirow{2}{*}{$\begin{array}{l}95 \% \text { CI } \\
\text { DA-CA }\end{array}$} & \multirow{2}{*}{$P$ value } \\
\hline & & $\mathrm{CA}(\mathrm{SD})$ & $\mathrm{DA}(\mathrm{SD})$ & $\mathrm{DA}-\mathrm{CA}(\mathrm{SD})$ & & \\
\hline \multirow{2}{*}{$4.00-4.99$} & $\mathrm{M}(7)$ & $4.62(0.23)$ & $5.37(0.26)$ & $0.75(0.18)$ & $0.58-0.93$ & 0.000 \\
\hline & $F(9)$ & $4.66(0.14)$ & $5.57(0.68)$ & $0.90(0.72)$ & $0.34-1.46$ & 0.006 \\
\hline \multirow{2}{*}{$5.00-5.99$} & M (12) & $5.77(0.10)$ & $6.60(0.80)$ & $0.83(0.79)$ & $0.33-1.33$ & 0.004 \\
\hline & $\mathrm{F}(20)$ & $5.63(0.34)$ & $6.90(0.77)$ & $1.26(0.66)$ & $0.95-1.58$ & 0.000 \\
\hline \multirow{2}{*}{$6.00-6.99$} & $\mathrm{M}(26)$ & $6.46(0.22)$ & $7.50(0.35)$ & $1.04(0.35)$ & $0.90-1.18$ & 0.000 \\
\hline & $\mathrm{F}(22)$ & $6.35(0.28)$ & $7.49(0.25)$ & $1.13(0.45)$ & $0.93-1.33$ & 0.000 \\
\hline \multirow{2}{*}{$7.00-7.99$} & $\mathrm{M}(28)$ & $7.43(0.25)$ & $8.08(0.46)$ & $0.66(0.42)$ & $0.5-0.82$ & 0.000 \\
\hline & $\mathrm{F}(40)$ & $7.41(0.29)$ & $8.40(0.83)$ & $0.98(0.69)$ & $0.76-1.20$ & 0.000 \\
\hline \multirow{2}{*}{$8.00-8.99$} & M (26) & $8.40(0.24)$ & $9.10(0.83)$ & $0.70(0.98)$ & $0.29-1.09$ & 0.058 \\
\hline & $\mathrm{F}(38)$ & $8.38(0.30)$ & $8.80(0.75)$ & $0.42(0.69)$ & $0.19-0.65$ & 0.001 \\
\hline \multirow{2}{*}{$9.00-9.99$} & $\mathrm{M}(30)$ & $9.43(0.31)$ & $10.40(0.98)$ & $0.97(0.85)$ & $0.65-1.28$ & 0.000 \\
\hline & $\mathrm{F}(24)$ & $9.42(0.30)$ & $9.78(0.82)$ & $0.36(0.83)$ & $0.01-0.71$ & 0.044 \\
\hline \multirow{2}{*}{$10.00-10.99$} & $\mathrm{M}(30)$ & $10.54(0.33)$ & $11.76(0.51)$ & $1.21(0.56)$ & $1.00-1.42$ & 0.000 \\
\hline & $\mathrm{F}(24)$ & $10.53(0.35)$ & $11.59(0.61)$ & $1.05(0.70)$ & $0.75-1.35$ & 0.000 \\
\hline \multirow{2}{*}{$11.00-11.99$} & M (16) & $11.37(0.17)$ & 11.55 (1.09) & $0.17(1.05)$ & $-0.38-0.73$ & 0.523 \\
\hline & $F(6)$ & $11.36(0.12)$ & $11.90(0.46)$ & $0.53(0.42)$ & $0.09-0.97$ & 0.026 \\
\hline \multirow{2}{*}{$12.00-12.99$} & $\mathrm{M}(30)$ & $12.40(0.31)$ & $13.10(1.27)$ & $0.69(1.18)$ & $0.25-1.14$ & 0.003 \\
\hline & $\mathrm{F}(12)$ & $12.45(0.26)$ & $13.20(1.15)$ & $0.74(1.05)$ & $0.07-1.41$ & 0.033 \\
\hline \multirow{2}{*}{$13.00-13.99$} & M (12) & $13.62(0.30)$ & $13.50(0.81)$ & $-0.12(0.69)$ & $-0.56-0.32$ & 0.557 \\
\hline & $\mathrm{F}(10)$ & $13.32(0.30)$ & $14.40(1.17)$ & $1.08(1.06)$ & $0.31-1.84$ & 0.011 \\
\hline \multirow{2}{*}{ Total } & $\mathrm{M}(217)$ & $9.27(2.43)$ & $10.04(2.44)$ & $0.76(0.85)$ & $0.65-0.88$ & 0.000 \\
\hline & $\mathrm{F}(205)$ & $8.48(2.27)$ & $9.31(2.30)$ & $0.83(0.78)$ & $0.72-0.94$ & 0.000 \\
\hline TOTAL & $M+F(422)$ & $8.89(2.38)$ & $9.69(2.40)$ & $0.80(0.82)$ & $0.72-0.87$ & 0.000 \\
\hline
\end{tabular}

TABLE 2: Mean difference ( \pm standard deviation) between dental age based on the Demirjian method and chronological age as determined by the different methods in boys.

\begin{tabular}{|c|c|c|c|c|}
\hline Age group $(n)$ & French-Canadian (SD) & Belgian (SD) & Kuwaiti (SD) & Saudi (SD) \\
\hline $4-5(7)$ & $0.75(0.18)$ & $-1.26(0.53)$ & $0.03(0.17)$ & NA \\
\hline $5-6(12)$ & $0.82(0.78)$ & $0.11(1.67)$ & $0.04(0.79)$ & NA \\
\hline $6-7(26)$ & $1.04(0.35)$ & $1.57(0.96)$ & $0.51(0.70)$ & NA \\
\hline $7-8(28)$ & $0.66(0.42)$ & $2.11(1.01)$ & $0.60(0.69)$ & $1.68(0.00)$ \\
\hline $8-9(26)$ & $0.69(0.98)$ & $2.81(1.33)$ & $0.85(0.92)$ & $1.22(0.77)$ \\
\hline $9-10(30)$ & $0.97(0.84)$ & $3.23(0.82)$ & $0.83(0.57)$ & $0.95(0.68)$ \\
\hline $10-11(30)$ & $1.21(0.56)$ & $3.05(0.48)$ & $0.60(0.48)$ & $0.80(0.43)$ \\
\hline $11-12(16)$ & $0.17(1.05)$ & $2.14(0.65)$ & $-0.39(0.62)$ & $-0.19(0.67)$ \\
\hline $12-13(30)$ & $0.69(1.18)$ & $1.91(0.53)$ & $-0.20(1.15)$ & $-0.19(0.88)$ \\
\hline $13-14(12)$ & $-0.12(0.69)$ & $1.20(0.86)$ & $-1.51(0.63)$ & $-1.22(0.41)$ \\
\hline Total (217) & $0.76(0.85)$ & $2.12(1.36)$ & $0.30(0.96)$ & $0.40(1.00)$ \\
\hline
\end{tabular}

weeks between the two rating sessions. Later, the author was the only rater for the developmental stages of the teeth.

\section{Results}

The Cronbach's alpha between the first rating and the second rating was 0.994 , indicating a high level of reproducibility.

Using the Demirjian method, DA, CA, and differences between DA and CA (DA-CA) for both genders and all age groups are presented in Table 1 . The paired $t$-test results indicated that the mean CA was 8.89 and the mean DA was
9.69. This mean indicated an overaging of the sample as by about 10 months, which held equally true for both sexes. The mean age difference was 0.77 (SD 0.85, CI 0.65-0.88) in boys and 0.83 (SD 0.79, CI 0.72-0.94) in girls. The mean differences between DA and CA were extremely statistically significant $(P<0.001)$, and therefore corrections for multiple comparisons were not used. The mean difference between the DA and CA ranged from -0.12 to 1.21 yrs in boys and from 0.42 to 1.26 yrs in girls. The differences in the means were statistically significant for all age groups and genders, except in 8-year-old, 11-year-old, and 13-year-old boys. 
TABLE 3: Mean difference ( \pm standard deviation) between dental age based on the Demirjian method and chronological age as determined by the different methods in girls.

\begin{tabular}{|c|c|c|c|c|}
\hline Age group $(n)$ & French-Canadian (SD) & Belgian (SD) & Kuwaiti (SD) & Saudi (SD) \\
\hline 4-5 (9) & $0.90(0.72)$ & $-0.36(1.41)$ & $0.62(0.52)$ & NA \\
\hline $5-6(20)$ & $1.26(0.66)$ & $1.38(1.36)$ & $0.95(0.69)$ & NA \\
\hline $6-7(22)$ & $1.13(0.45)$ & $1.96(0.85)$ & $0.92(0.62)$ & NA \\
\hline $7-8(40)$ & $0.98(0.65)$ & $2.82(1.22)$ & $1.24(0.82)$ & $1.51(0.57)$ \\
\hline $8-9(38)$ & $0.42(0.69)$ & $2.73(0.83)$ & $0.76(0.53)$ & $0.90(0.57)$ \\
\hline $9-10(24)$ & $0.36(0.83)$ & $2.95(1.02)$ & $0.56(0.67)$ & $0.60(0.65)$ \\
\hline $10-11(24)$ & $1.05(0.70)$ & $3.28(0.68)$ & $0.50(0.90)$ & $0.76(0.56)$ \\
\hline $11-12(6)$ & $0.53(0.42)$ & $2.68(0.04)$ & $0.15(0.34)$ & $0.17(0.27)$ \\
\hline $12-13(12)$ & $0.74(1.05)$ & $2.03(0.47)$ & $0.25(1.35)$ & $-0.09(0.98)$ \\
\hline $13-14(10)$ & $1.08(1.06)$ & $1.79(0.41)$ & $-0.15(1.34)$ & $0.88(1.43)$ \\
\hline Total (205) & $0.83(0.78)$ & $2.40(1.26)$ & $0.74(0.85)$ & $0.84(0.84)$ \\
\hline
\end{tabular}

TABLE 4: A post hoc test comparing several methods for age estimation in boys.

\begin{tabular}{|c|c|c|c|c|c|c|}
\hline \multicolumn{2}{|c|}{ DiffageMale Scheffe } & \multicolumn{5}{|c|}{ Multiple comparisons } \\
\hline \multirow{2}{*}{ (I) group } & \multirow{2}{*}{ (J) group } & \multirow{2}{*}{ Mean difference $(\mathrm{I}-\mathrm{J})$} & \multirow{2}{*}{ Std. error } & \multirow{2}{*}{ Sig. } & \multicolumn{2}{|c|}{$95 \%$ confidence interval } \\
\hline & & & & & Lower bound & Upper bound \\
\hline \multirow{3}{*}{ French-Canadian } & Belgian & $-1.35373^{*}$ & .10256 & .000 & -1.6411 & -1.0664 \\
\hline & Kuwaiti & $.46452^{*}$ & .10256 & .000 & .1772 & .7518 \\
\hline & Saudi & $.36993^{*}$ & .11632 & .018 & .0441 & .6958 \\
\hline \multirow{3}{*}{ Belgian } & French-Canadian & $1.35373^{*}$ & .10256 & .000 & 1.0664 & 1.6411 \\
\hline & Kuwaiti & $1.81825^{*}$ & .10256 & .000 & 1.5309 & 2.1056 \\
\hline & Saudi & $1.72366^{*}$ & .11632 & .000 & 1.3978 & 2.0495 \\
\hline \multirow{3}{*}{ Kuwaiti } & French-Canadian & $-.46452^{*}$ & .10256 & .000 & -.7518 & -.1772 \\
\hline & Belgian & $-1.81825^{*}$ & .10256 & .000 & -2.1056 & -1.5309 \\
\hline & Saudi & -.09459 & .11632 & .882 & -.4205 & .2313 \\
\hline \multirow{3}{*}{ Saudi } & French-Canadian & $-.36993^{*}$ & .11632 & .018 & -.6958 & -.0441 \\
\hline & Belgian & $-1.72366^{*}$ & .11632 & .000 & -2.0495 & -1.3978 \\
\hline & Kuwaiti & .09459 & .11632 & .882 & -.2313 & .4205 \\
\hline
\end{tabular}

${ }^{*}$ The mean difference is significant at the 0.05 level.

TABLE 5: A post hoc test comparing several methods for age estimation in girls.

\begin{tabular}{|c|c|c|c|c|c|c|}
\hline \multicolumn{2}{|c|}{ DiffageFemale Scheffe } & \multicolumn{5}{|c|}{ Multiple comparisons } \\
\hline \multirow{2}{*}{ (I) group } & \multirow{2}{*}{ (J) group } & \multirow{2}{*}{ Mean difference $(\mathrm{I}-\mathrm{J})$} & \multirow{2}{*}{ Std. error } & \multirow{2}{*}{ Sig. } & \multicolumn{2}{|c|}{$95 \%$ confidence interval } \\
\hline & & & & & Lower bound & Upper bound \\
\hline \multirow{3}{*}{ French-Canadian } & Belgian & $-1.57024^{*}$ & .09554 & .000 & -1.8379 & -1.3026 \\
\hline & Kuwaiti & .09220 & .09554 & .818 & -.1755 & .3599 \\
\hline & Saudi & -.00907 & .10794 & 1.000 & -.3115 & .2934 \\
\hline \multirow{3}{*}{ Belgian } & French-Canadian & $1.57024^{*}$ & .09554 & .000 & 1.3026 & 1.8379 \\
\hline & Kuwaiti & $1.66244^{*}$ & .09554 & .000 & 1.3948 & 1.9301 \\
\hline & Saudi & $1.56118^{*}$ & .10794 & .000 & 1.2587 & 1.8636 \\
\hline \multirow{3}{*}{ Kuwaiti } & French-Canadian & -.09220 & .09554 & .818 & -.3599 & .1755 \\
\hline & Belgian & $-1.66244^{*}$ & .09554 & .000 & -1.9301 & -1.3948 \\
\hline & Saudi & -.10126 & .10794 & .830 & -.4037 & .2012 \\
\hline \multirow{3}{*}{ Saudi } & French-Canadian & .00907 & .10794 & 1.000 & -.2934 & .3115 \\
\hline & Belgian & $-1.56118^{*}$ & .10794 & .000 & -1.8636 & -1.2587 \\
\hline & Kuwaiti & .10126 & .10794 & .830 & -.2012 & .4037 \\
\hline
\end{tabular}

\footnotetext{
${ }^{*}$ The mean difference is significant at the 0.05 level.
} 
TABLE 6: Scheffe's post hoc homogeneous subsets showing overall differences between the methods used at $P=0.05$ for boys.

\begin{tabular}{lccc}
\hline Method used $(n)$ & \multicolumn{3}{c}{ Subset for alpha $=0.05$} \\
& $\mathrm{a}^{*}$ & $\mathrm{~b}^{*}$ & $\mathrm{c}^{*}$ \\
\hline Kuwaiti (217) & 0.30 & & \\
Saudi (138) & 0.39 & & \\
$\begin{array}{l}\text { French-Canadian (217) } \\
\text { Belgian (217) }\end{array}$ & 0.76 & 2.12 \\
\hline Significance & 0.86 & 1.00 & 1.00 \\
\hline${ }^{*}$ ref
\end{tabular}

*Values that are not significantly different based on the post hoc Scheffé contrast will have the same superscript, and values that are significantly different will have different superscripts.

TABLE 7: Scheffe's post hoc homogeneous subsets showing overall differences between the methods used at $P=0.05$ for girls.

\begin{tabular}{lcc}
\hline Method used $(n)$ & \multicolumn{2}{c}{ Subset for alpha $=0.05$} \\
& $\mathrm{a}^{*}$ & $\mathrm{~b}^{*}$ \\
\hline Kuwaiti (205) & 0.74 & \\
Saudi (132) & 0.84 & 2.40 \\
$\begin{array}{l}\text { French-Canadian (205) } \\
\text { Belgian (205) }\end{array}$ & 0.83 & 1.00 \\
\hline Significance & 0.80 & \\
*Values that are not significantly different based on the post hoc Scheffé \\
$\begin{array}{l}\text { contrast will have the same superscript, and values that are significantly } \\
\text { different will have different superscripts. }\end{array}$
\end{tabular}

Tables 2 and 3 present the differences between the DACA when assessed using population-specific curves, taking age group as a factor. From the results, it appears that the original Demirjian method and its modifications consistently overestimated the age of the sample. One-way ANOVA found significant differences in estimation between the different methods for both boys $(F=127.88, P<0.001)$ and girls $(F=136.58, P<0.001)$. However, post hoc tests revealed that the mean difference in estimation based on the Kuwaiti and Saudi curves for boys was not statistically significant (Table 4). For girls, the mean differences between the Kuwaiti, Saudi, and the original French-Canadian curves were not statistically significant (Table 5). Scheffé's homogeneous subsets found that when boys were compared, the tables designed specifically for Arab (Kuwaiti and Saudi) populations had a significantly lower error than the tables designed for Caucasian + Amerindian (French-Canadian) and European (Belgian) populations (Table 6). A similar comparison between girls found that there were no statistical differences between the original Demirjian method and the curves designed for Arab populations (Table 7). Figures 1 and 2 show the fitting curve for the study population as compared to the three existing curves for boys and girls.

Missing data for age groups younger than 7.5 years made the comparison between the present sample and existing curves designed for Saudi population impossible. Different relationships between chronological age, on one hand, and dental age were explored. Two models: the linear and the cubic were selected. Figures 3 and 4 present linear regressions
TABLE 8: Cubic equations for boys and girls.

$Y=-7.424+0.741 x-0.013 x^{2}+0.00007863 x^{3}$ (males)

$Y=-8.269+0.757 x-0.013 x^{2}+0.00007782 x^{3}$ (females)

$Y$ is age, and $x$ is maturation score.

for chronological age versus estimated ages of boys and girls with $95 \%$ confidence and prediction intervals. The equation can be used to estimate mean age based on the Demirjian dental age. Table 8 and Figures 5 and 6 present the cubic functions between age and maturation scores. New genderspecific dental maturity tables were developed based on a third-degree regression because it proved to be the best fit to the plots (Tables 9 and 10).

\section{Discussion}

Dental and skeletal developments provide measures of physiological age to predict the optimal timing for treatment in orthodontic, orthopedic, or pediatric clinical practice or to estimate the chronological age of skeletal remains in forensic or archeological contexts [12]. Dental development is less affected by environmental quality than skeletal development [12].

Several methods have been proposed for assessing dental development, which is generally referred to as dental aging. Dental aging appears in two forms: calcification (tooth development) and eruption patterns [13]. Eruption refers to emergence of the tooth through the gum, rather than to emergence from the bone or reaching the occlusal plane [13]. This makes it impossible to use eruption for age estimation on skeletal remains in forensics. Tooth emergence may be influenced significantly by local exogenous factors, such as infection, obstruction, crowding, and premature extraction of the deciduous predecessor or adjacent permanent teeth [12]. Most of the disadvantages can be avoided by using stages of tooth formation from radiographical data on the calcification of teeth to determine dental maturity from in utero until the late twenties, if the third molar is used.

The Demirjian eight-stage method is one of the principal methods used to quantify the degree of maturity from the age from 3 to 17 years [1]. Although the Demirjian method performs well in terms of observer agreement and correlation between the estimated age and true age [14] (which is in agreement with the current study), the Demirjian original French-Canadian standards do not accurately estimate the chronological age in all samples [1, 15-19].

It is important to remember that the difference in chronological age and dental age may be attributed to different factors, including the accuracy of the method, examiner's training and experience, sample size and distribution, and statistic approach to the obtained results [20]. However, it is equally important to realize that no age estimation will accurately determine the exact age for every individual as development naturally varies between individuals. Forensic science uses age ranges when estimating age for just this reason [13]. Differences between real age and estimated age up to 12 months were considered to be within normal standards 


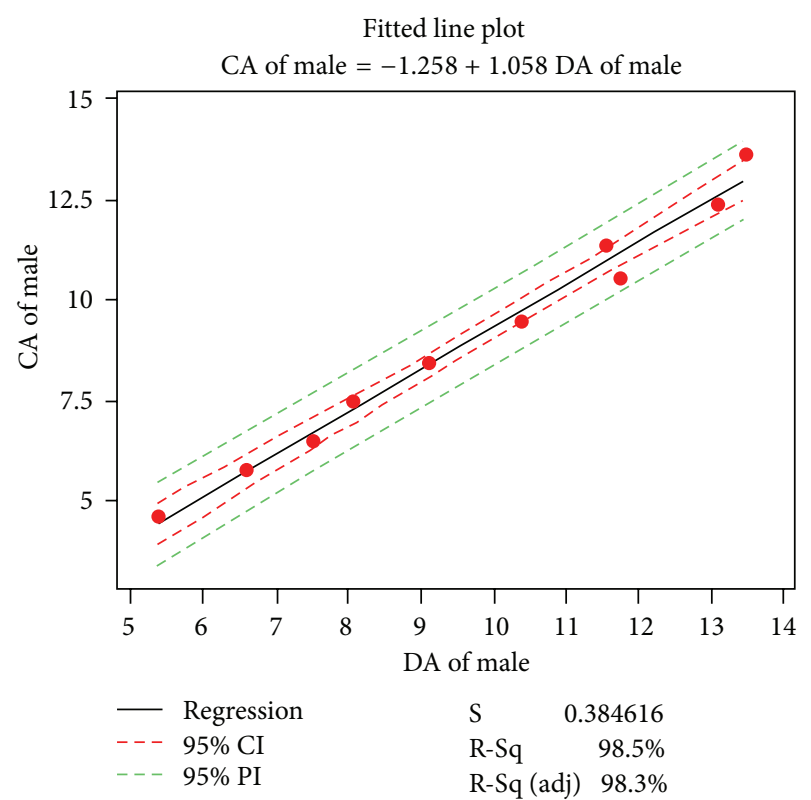

FIGURE 3: Regression of mean chronological versus estimated ages of our Saudi males with 95\% confidence and prediction intervals; $R^{2}=0.985$.

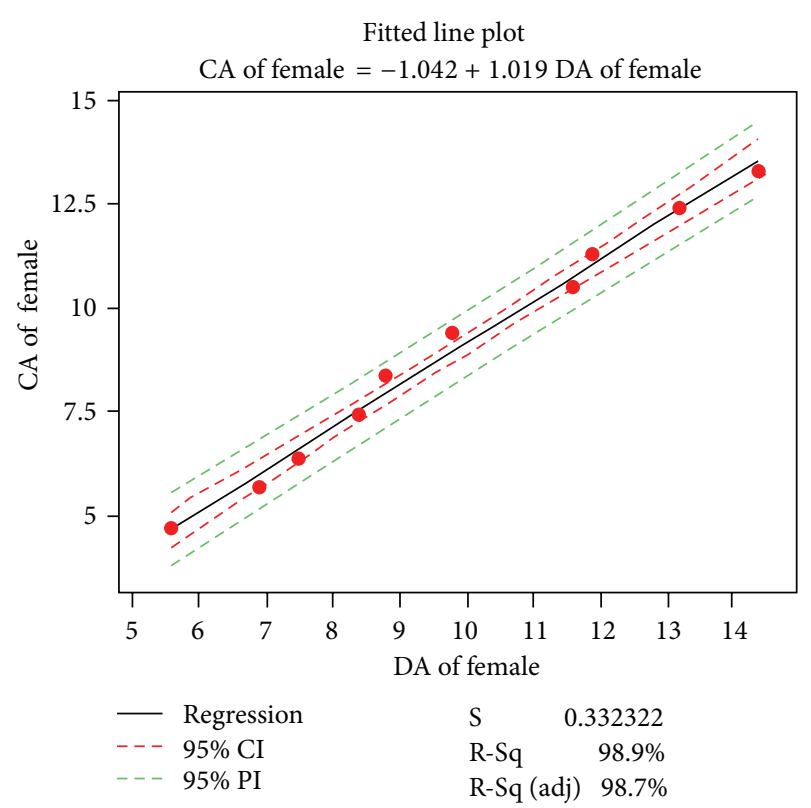

Figure 4: Regression of mean chronological versus estimated ages of our Saudi females with 95\% confidence and prediction intervals; $R^{2}=0.989$.

for some authors [21]; however, smaller intervals are strived for by other authors [22], hence the construction of the "population-specific Demirjian curves."

The results of the current study corroborate the results of previous studies $[10,12]$ that examined the applicability of the Demirjian method to similar populations. A study [11] assessing the dental age in Saudi children aged from 8.5 to 17 years found that Saudi children from Riyadh were

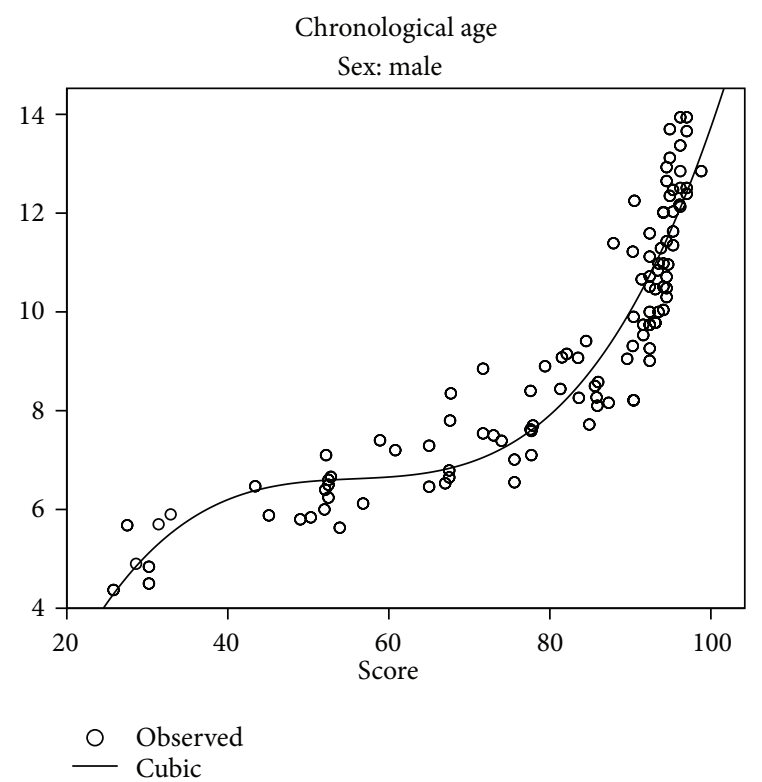

FIGURE 5: Scatter plots of maturity score against chronological age in Saudi boys.

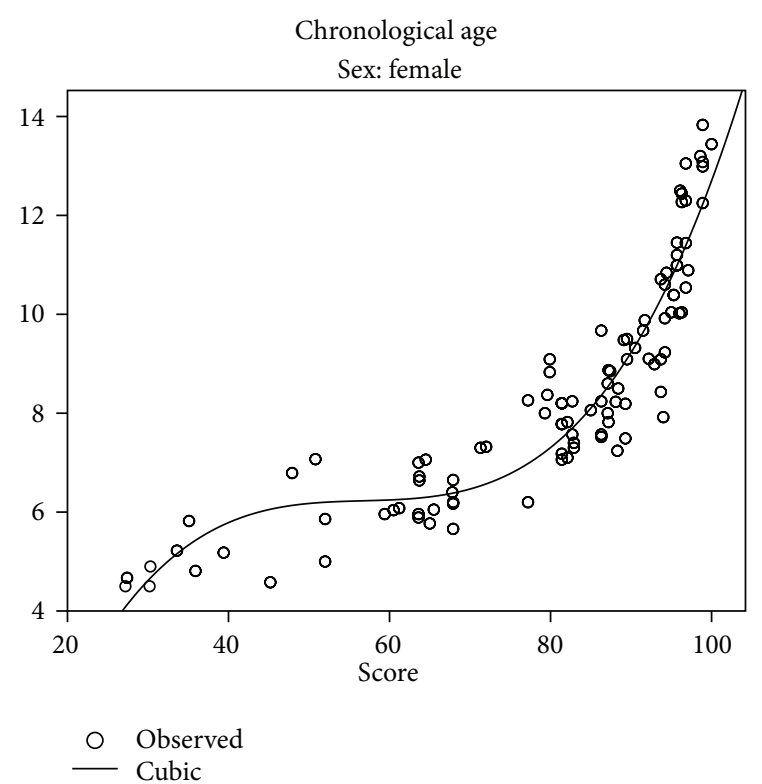

FIGURE 6: Scatter plots of maturity score against chronological age in Saudi girls.

overestimated by 0.3 years for boys and 0.4 years for girls. Similar results were reported on Kuwaiti children aged from 3 to $14 \mathrm{yrs}$, but the overestimations were $0.71 \mathrm{yrs}$ for boys and 0.67 for girls [10]. The samples constituting the three studies from Saudi Arabia and Kuwait are from the same ancestry, geographically close to each other, and exposed to similar dietary and behavior patterns [23]. The only difference is that the sample in the Al-Emran study was somewhat larger $(N=490)$ and older in age (from 7.5 to $17 \mathrm{yrs})$. The present study has found that overall overestimations are 
TABLE 9: Predicted age per maturity score in Saudi boys using the developed function formula based on the Demirjian method.

\begin{tabular}{|c|c|c|c|}
\hline 25.8 & 4.28746 & 85.6 & 8.92035 \\
\hline 27.5 & 4.63997 & 85.8 & 8.96403 \\
\hline 28.6 & 4.84737 & 85.9 & 8.98608 \\
\hline 30.2 & 5.12152 & 86 & 9.00827 \\
\hline 31.4 & 5.30676 & 87.3 & 9.30993 \\
\hline 32.9 & 5.51512 & 87.9 & 9.45756 \\
\hline 43.4 & 6.38282 & 89.6 & 9.90584 \\
\hline 45.1 & 6.4484 & 90.3 & 10.10369 \\
\hline 49 & 6.54762 & 90.4 & 10.1326 \\
\hline 50.3 & 6.56851 & 90.5 & 10.16168 \\
\hline 52 & 6.58939 & 91.4 & 10.43079 \\
\hline 52.1 & 6.59044 & 91.6 & 10.49243 \\
\hline 52.2 & 6.59147 & 92.4 & 10.74578 \\
\hline 52.8 & 6.5973 & 93.1 & 10.97653 \\
\hline 53.9 & 6.60675 & 93.4 & 11.07805 \\
\hline 56.8 & 6.62817 & 93.5 & 11.11225 \\
\hline 58.9 & 6.64555 & 93.8 & 11.21591 \\
\hline 60.8 & 6.66675 & 94.1 & 11.32118 \\
\hline 65 & 6.74862 & 94.5 & 11.46407 \\
\hline 67 & 6.81243 & 94.7 & 11.53661 \\
\hline 67.5 & 6.83155 & 95.3 & 11.75866 \\
\hline 67.6 & 6.83554 & 96.1 & 12.06518 \\
\hline 67.7 & 6.83958 & 96.2 & 12.10434 \\
\hline 71.7 & 7.05245 & 97 & 12.42458 \\
\hline 73 & 7.14604 & 98.8 & 13.19098 \\
\hline 74 & 7.22733 & & \\
\hline 75.6 & 7.37547 & & \\
\hline 77.6 & 7.59454 & & \\
\hline 77.7 & 7.60654 & & \\
\hline 77.9 & 7.63085 & & \\
\hline 79.4 & 7.8268 & & \\
\hline 81.3 & 8.11119 & & \\
\hline 81.5 & 8.1436 & & \\
\hline 82.1 & 8.24375 & & \\
\hline 83.5 & 8.49501 & & \\
\hline 83.6 & 8.51392 & & \\
\hline 84.5 & 8.69009 & & \\
\hline 84.9 & 8.77189 & & \\
\hline
\end{tabular}

statistically significant, but that when comparing age groups in the three studies, the results were less consistent as some groups showed significant differences between true age and estimated age, and some did not.

The results here confirm the necessity of developing specific scores or curves for specific populations, as agreed by most authors [22]. The regression models used here resemble those proposed by Cruz-Landeira et al. [24] and differ from most of the previously published researches [3] considering age as the independent variable and the score as the dependent. Here, we inverted the variables, considering the chronological age (parameter that is wanted to be calculated in a real forensic case) as a function of the maturity score
TABLE 10: Predicted age per maturity score in Saudi girls using the developed function formula based on the Demirjian method.

\begin{tabular}{|c|c|c|c|}
\hline 27.2 & 4.08377 & 88.1 & 8.75631 \\
\hline 27.4 & 4.12524 & 88.3 & 8.80327 \\
\hline 30.2 & 4.64983 & 88.4 & 8.82697 \\
\hline 30.3 & 4.66671 & 89.1 & 8.99705 \\
\hline 33.6 & 5.15701 & 89.3 & 9.04699 \\
\hline 35.1 & 5.3399 & 89.5 & 9.09754 \\
\hline 35.9 & 5.42803 & 90.5 & 9.35954 \\
\hline 39.4 & 5.74337 & 91.5 & 9.63728 \\
\hline 45.2 & 6.05669 & 91.7 & 9.69475 \\
\hline 47.9 & 6.13495 & 92.2 & 9.84131 \\
\hline 50.8 & 6.18559 & 92.9 & 10.05345 \\
\hline 52 & 6.19902 & 93.7 & 10.30601 \\
\hline 59.4 & 6.24147 & 94 & 10.40356 \\
\hline 60.5 & 6.2489 & 94.2 & 10.46946 \\
\hline 61.2 & 6.25469 & 94.4 & 10.53605 \\
\hline 63.6 & 6.28319 & 95 & 10.74007 \\
\hline 63.6 & 6.28319 & 95.3 & 10.84448 \\
\hline 63.7 & 6.28473 & 95.7 & 10.98622 \\
\hline 64.5 & 6.29826 & 96 & 11.09443 \\
\hline 65 & 6.30787 & 96.1 & 11.13086 \\
\hline 65.5 & 6.31843 & 96.3 & 11.20428 \\
\hline 67.8 & 6.38106 & 96.8 & 11.39107 \\
\hline 67.9 & 6.38436 & 97.1 & 11.50539 \\
\hline 71.3 & 6.53046 & 98.6 & 12.10261 \\
\hline 72 & 6.56966 & 98.9 & 12.22728 \\
\hline 77.2 & 6.98061 & 100 & 12.69963 \\
\hline 79.3 & 7.21594 & & \\
\hline 79.6 & 7.25324 & & \\
\hline 79.9 & 7.29151 & & \\
\hline 81.4 & 7.49764 & & \\
\hline 82.1 & 7.60258 & & \\
\hline 82.7 & 7.69714 & & \\
\hline 82.9 & 7.72963 & & \\
\hline 85 & 8.10086 & & \\
\hline 86.3 & 8.35951 & & \\
\hline 87.1 & 8.53019 & & \\
\hline 87.2 & 8.55216 & & \\
\hline 87.4 & 8.59652 & & \\
\hline
\end{tabular}

(the known parameter). The cubic model proved to be the best as, after exploring several models, it provided the best fit between maturation scores and chronological age (Figures 5 and 6 ).

Although the sample size of the current study seems smaller than that in similar studies, this is not necessarily a limitation in forensic cases [25]. Power analysis for each age group in our study ranged from 0.88 to 1.0. In addition, the results of this study corroborate the results of our previous study [26] which had a smaller sample $(N=176)$. Although Scheffé's procedure followed here is the most popular, flexible, and conservative of the post hoc procedures, it is also the least statistically powerful procedure because it involves contrasts 
of more than two means at the same time. However, due to the extreme significant (or nonsignificant) results shown in Tables 4 and 5, it is unlikely that the test leads to Type II errors [27].

As presented in Figures 5 and 6, a 100\% maturity is achieved at a mean age of 13.2 for males and 12.7 for females. This suggests that the Demirjian method is inadequate after the age of 13 in Saudi population. Other researchers [24] have reported that $100 \%$ of maturity was achieved for girls at the age of 12 in a Spanish sample and at the age of 14.1 in a Venezuelan sample; boys showed a median growth delay of 1 year compared to girls. The gender difference is most likely biological and as most maturation events (e.g., height, and sexual maturation) is faster in girls. This is in agreement with this study, where girls were dentally more advanced than boys.

After an evaluation of findings to the literature, it may be concluded that although over- and underestimations result from the Demirjian method, it remains a valuable way to evaluate the age of a child based on dentition. The Demirjian method may not yield an exact age in every case; however, it seems to be a clinically acceptable method to study the pattern of growth within a certain population (e.g., normal children versus children with disabilities) or between different populations. As new curves for populations are more accurate than the original curves, new curves were developed which require further validation studies.

\section{References}

[1] A. Demirjian, H. Goldstein, and J. M. Tanner, "A new system of dental age assessment," Human Biology, vol. 45, no. 2, pp. 211227, 1973.

[2] R. J. Hegde and P. B. Sood, "Dental maturity as an indicator of chronological age: radiographic evaluation of dental age in 6 to 13 years children of Belgaum using Demirjian methods," Journal of the Indian Society of Pedodontics and Preventive Dentistry, vol. 20, no. 4, pp. 132-138, 2002.

[3] G. Willems, A. Van Olmen, B. Spiessens, and C. Carels, "Dental age estimation in Belgian children: Demirjian's technique revisited," Journal of Forensic Sciences, vol. 46, no. 4, pp. 893-895, 2001.

[4] G. Willems, "A review of the most commonly used dental age estimation techniques," Journal of Forensic Odonto-Stomatology, vol. 19, no. 1, pp. 9-17, 2001.

[5] U. Hägg and L. Matsson, "Dental maturity as an indicator of chronological age: the accuracy and precision of three methods," European Journal of Orthodontics, vol. 7, no. 1, pp. 2534, 1985.

[6] L. E. Davidson and H. D. Rodd, "Interrelationship between dental age and chronological age in Somali children," Community Dental Health, vol. 18, no. 1, pp. 27-30, 2001.

[7] V. M. Phillips and T. J. Van Wyk Kotze, "Testing standard methods of dental age estimation by moorrees, fanning and hunt and demirjian, goldstein and tanner on three south african children samples," Journal of Forensic Odonto-Stomatology, vol. 27, no. 2, pp. 20-28, 2009.

[8] V. M. Phillips and T. J. Van Wyk Kotze, "Dental age related tables for children of various ethnic groups in South Africa," Journal of Forensic Odonto-Stomatology, vol. 27, no. 2, pp. 29-44, 2009.
[9] N. Chaillet, G. Willems, and A. Demirjian, "Dental maturity in Belgian children using Demirjian's method and polynomial functions: new standard curves for forensic and clinical use," Journal of Forensic Odonto-Stomatology, vol. 22, no. 2, pp. 1827, 2004.

[10] M. A. Qudeimat and F. Behbehani, "Dental age assessment for Kuwaiti children using Demirjian's method," Annals of Human Biology, vol. 36, no. 6, pp. 695-704, 2009.

[11] S. Al-Emran, "Dental age assessment of 8.5 to 17 year-old Saudi children using Demirjian's method," Journal of Contemporary Dental Practice, vol. 9, no. 3, pp. 064-071, 2008.

[12] H. Cardoso, "Differential sensitivity in growth and development of dental and skeletal tissue to environmental quality," Arquivos de Medicina, vol. 21, no. 1, pp. 19-23, 2007.

[13] N. M. Burt, Testing the Demirjian method and the international Demirjian method on an urban American sample [M.S. thesis], Michigan State University, 2007.

[14] S. J. AlQahtani, M. P. Hector, and H. M. Liversidge, "Brief communication: the London atlas of human tooth development and eruption," American Journal of Physical Anthropology, vol. 142, no. 3, pp. 481-490, 2010.

[15] M. Nyström, J. Haataja, M. Kataja, M. Evälahti, L. Peck, and E. Kleemola-Kujala, "Dental maturity in Finnish children, estimated from the development of seven permanent mandibular teeth," Acta Odontologica Scandinavica, vol. 44, no. 4, pp. 193198, 1986.

[16] H. Mörnstad, M. Reventlid, and A. Teivens, "The validity of four methods for age determination by teeth in Swedish children: a multicentre study," Swedish dental journal, vol. 19, no. 4, pp. 121130, 1995.

[17] V. Staaf, H. Mörnstad, and U. Welander, "Age estimation based on tooth development: a test of reliability and validity," Scandinavian Journal of Dental Research, vol. 99, no. 4, pp. 281286, 1991.

[18] I. H. Leurs, E. Wattel, I. H. A. Aartman, E. Etty, and B. PrahlAndersen, "Dental age in Dutch children," European Journal of Orthodontics, vol. 27, no. 3, pp. 309-314, 2005.

[19] E. S. Tunc and A. E. Koyuturk, "Dental age assessment using Demirjian's method on northern Turkish children," Forensic Science International, vol. 175, no. 1, pp. 23-26, 2008.

[20] L. Ferrante and R. Cameriere, "Statistical methods to assess the reliability of measurements in the procedures for forensic age estimation," International Journal of Legal Medicine, vol. 123, no. 4, pp. 277-283, 2009.

[21] M. E. L. de Moraes, M. S. Bastos, L. R. D. A. dos Santos, J. C. D. M. Castilho, L. C. de Moraes, and E. Medici Filho, "Dental age in patients with Down syndrome," Brazilian Oral Research, vol. 21, no. 3, pp. 259-264, 2007.

[22] N. Chaillet, M. Nyström, and A. Demirjian, "Comparison of dental maturity in children of different ethnic origins: international maturity curves for clinicians," Journal of Forensic Sciences, vol. 50, no. 5, pp. 1164-1174, 2005.

[23] A. O. Musaiger, "Nutritional status of mothers and children in the Arab Gulf countries," Health Promotion International, vol. 5, no. 4, pp. 259-268, 1990.

[24] A. Cruz-Landeira, J. Linares-Argote, M. Martínez-Rodríguez, M. S. Rodríguez-Calvo, X. L. Otero, and L. Concheiro, "Dental age estimation in Spanish and Venezuelan children. Comparison of Demirjian and Chaillet's scores," International Journal of Legal Medicine, vol. 124, no. 2, pp. 105-112, 2010. 
[25] S. Flood, W. Michell, C. Oxnard, B. Turlach, and J. McGeachie, "To evaluate the utility of smaller sample sizes when assessing dental maturity curves for forensic age estimation," Journal of Forensic Sciences, vol. 56, no. 6, pp. 1604-1610, 2011.

[26] Z. D. Baghdadi and S. C. Pani, "Accuracy of population-specific Demirjian curves in the estimation of dental age of Saudi children," International Journal of Paediatric Dentistry, vol. 22, no. 2, pp. 125-131, 2012.

[27] R. A. Armstrong and A. Hilton, "The use of analysis of variance (ANOVA) in applied microbiology," Microbiologist, vol. 5, pp. 18-21, 2004. 


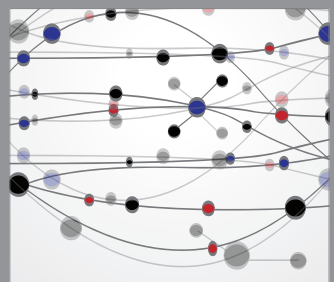

The Scientific World Journal
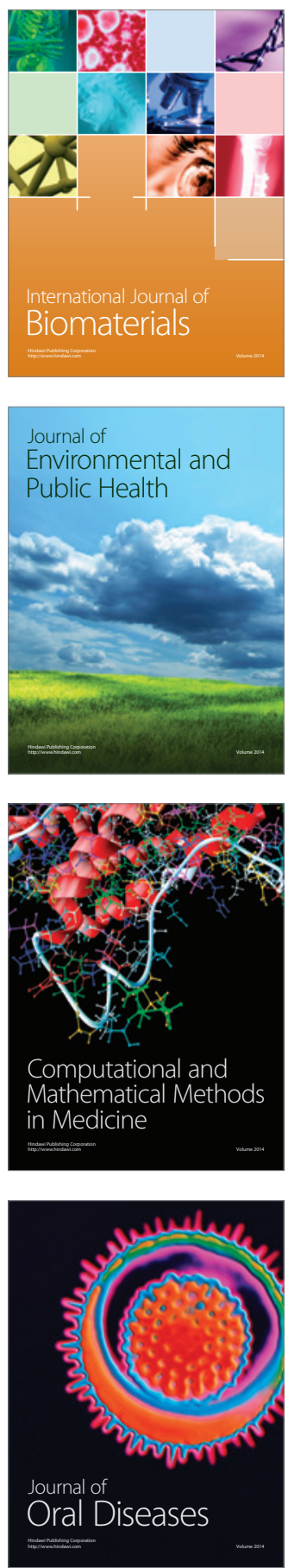
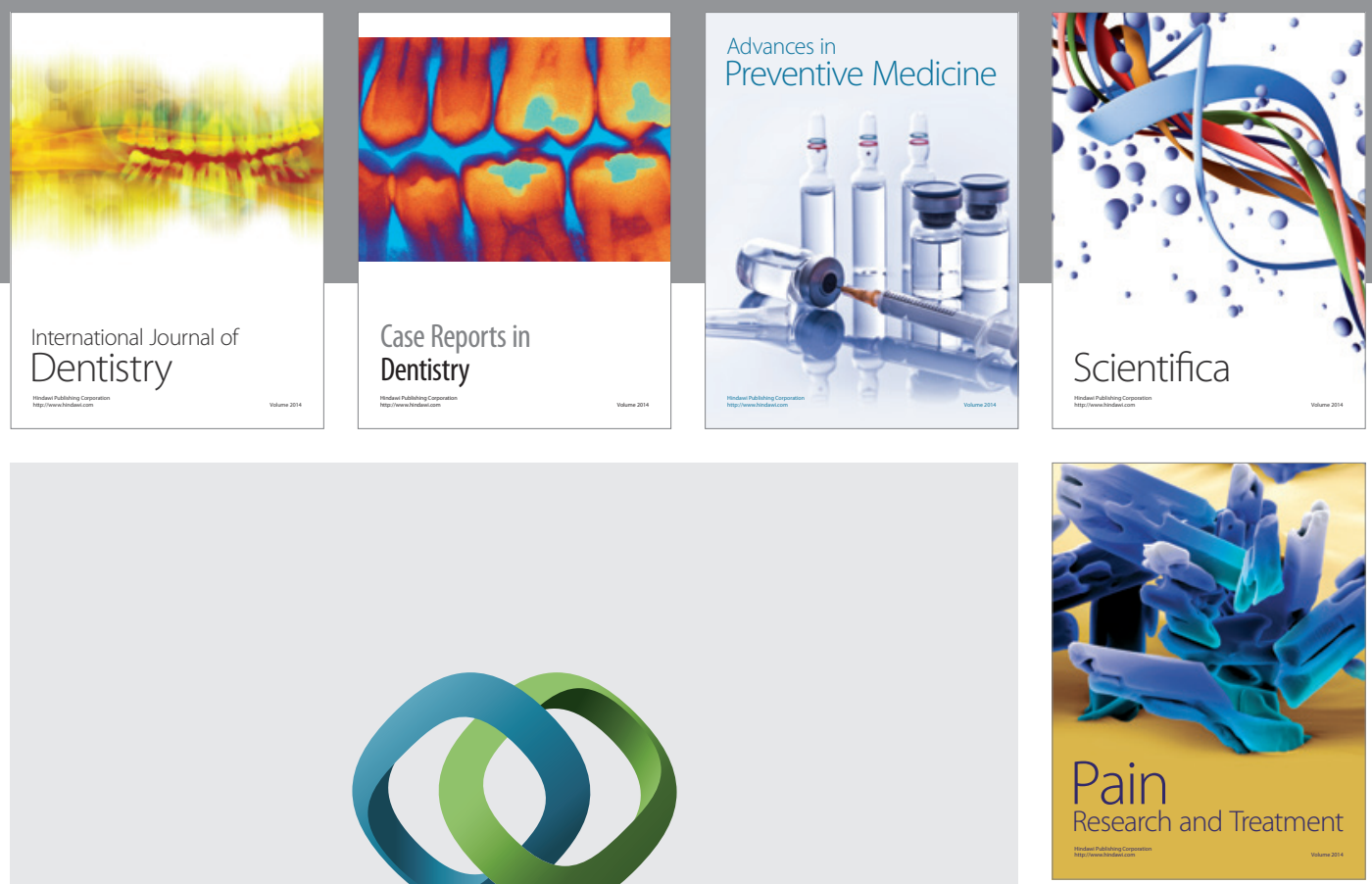

\section{Hindawi}

Submit your manuscripts at

http://www.hindawi.com
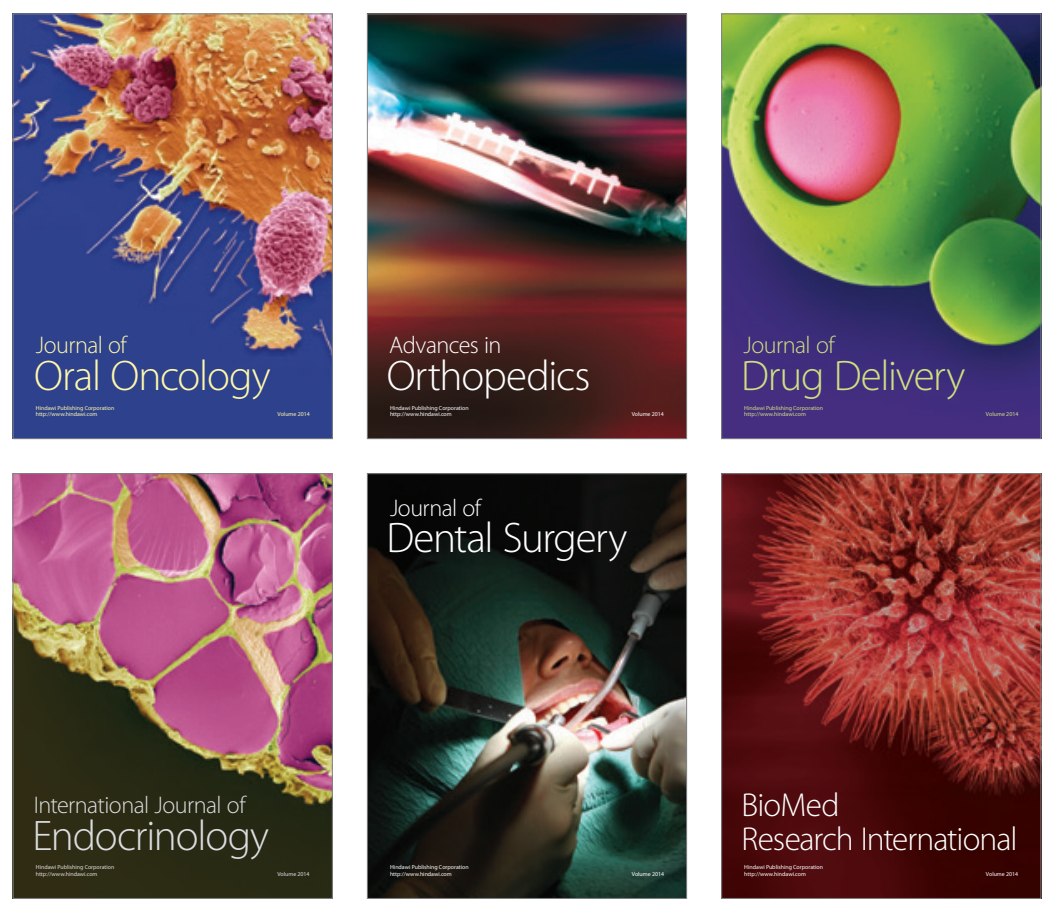

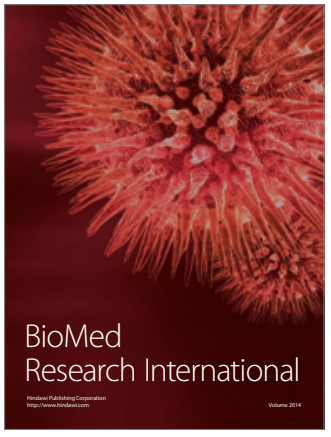

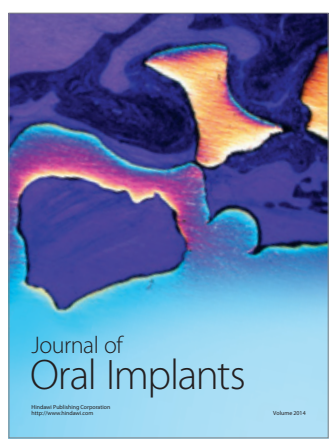
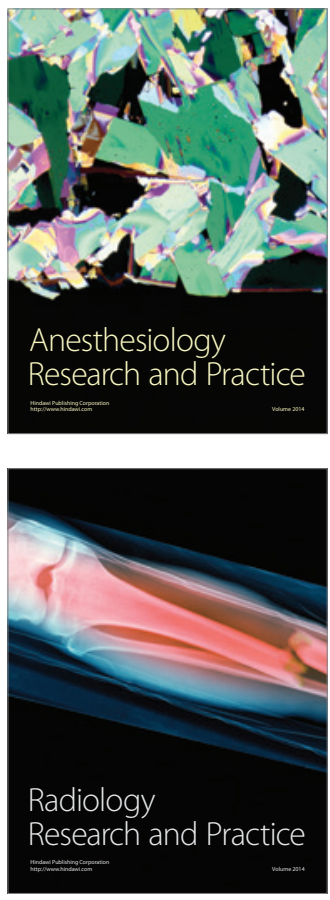